\title{
Parental Bonding and Psychological Well-Being among Young Adults
}

\author{
$\mathrm{J} \mathrm{Indumathy}^{1 *}$, K Ashwini ${ }^{2}$
}

\section{ABSTRACT}

The study on Parental Bonding and Psychological Well-being was conducted in Sriperumbudur among 60 young adults. The tools used were Parental Bonding Instrument and Psychological General Well - being Index. The bonding or attachment that a child has with parents have a great impact on their personality traits and well - being. Children who have a secure attachment with their parents tend to be less at the risk of any mental disorders. Parents these days are both employed and the children are left with the servant maids or at crèches, wherein they lose the bonding that has to be received from their parents. In some cases the parents are over protective to the children and restrict them in almost every single thing. This lack of parental bonding or over protectiveness may affect the well - being of the child in the later years. The present study is to know the bonding style of parents with their children and the effect of it on the psychological well-being of the individual. The results indicated that there is a significant correlation between parental care, control and psychological well - being.

Keywords: Parental Bonding, Psychological Well - Being, Young Adults

\section{"It is not managing a child but raising a human being"}

Parents tend to have a crucial role in the lives of their children namely, teacher, playmate, caregiver and disciplinarian. The bonding or attachment that a child has with parents have a great impact on their personality and well - being. Children who have a secure attachment with their parents tend to be less at the risk of any mental disorders. Parents these days are both employed and the children are left with the servant maids or at crèches, wherein they lose the bonding that has to be received from their parents. The parent - child attachment is an excellent predictor of a child's later social and emotional development. In some cases the parents are over protective to the children and restrict them in almost every single thing. This lack of parental bonding or over protectiveness may affect the well - being and social competency of the child in the later years.

\footnotetext{
${ }^{1}$ M.Sc. Counselling Psychology, Rajiv Gandhi National Institute of Youth Development, Sriperambudur, India

${ }^{2}$ M.Sc. Counselling Psychology, Rajiv Gandhi National Institute of Youth Development, Sriperambudur, India *Responding Author
}

Received: January 31, 2017; Revision Received: February 18, 2017; Accepted: February 24, 2017

(C) 2017 Indumathy J, Ashwini K; licensee IJIP. This is an Open Access Research distributed under the terms of the Creative Commons Attribution License (www.creativecommons.org/licenses/by/2.0), which permits unrestricted use, distribution, and reproduction in any Medium, provided the original work is properly cited. 


\section{Parental Bonding and Psychological Well-Being among Young Adults}

\section{Parental Bonding}

Parental Bonding is an important indicator that gives a huge insight into a parent - child relationship. It can be said as an attachment between the child and the parent. The attachment theory is based on the idea that there are individual differences in terms of how infants get emotionally bonded to their caregivers and how these first attachment experiences influence the future developments of infants in social, cognitive and emotional aspects (Bowlby, 1969; 1977). Through bonding the child learns about themselves and the world around them.

\section{Importance of Parental Bonding}

Parental bonding is very important for the normal development of an individual. The parent child relationship has a great influence on an individual's development than any other relationship. It tends to be the foundation for all other relationships that an individual forms in life. The bond is the source of love, trust, intimacy and security. This relationship would nourish well - being or may cause a scar in life.

Researchers claim that children who have a strong bond with parents are likely to develop a positive, responsive companion or intimacy, and would be better at adapting to difficult peers by asserting their needs. Children with a secure and caring bond with parents tend to come to a new peer relationship with positive beliefs and expectations. The child's first relationship with primary caregivers helps in learning what can and cannot be expected out of others.

The importance of bonding with the primary caregiver cannot be overestimated. Failure or lack of bonding may profoundly affect the future development and the ability to form healthy relationships as an adult. Fortunately, human beings are not completely dependent on the early moments. They have many opportunities to bond appropriately throughout the first year of life. There are also instances where mothers who adopt babies and even older children are able to form intimate attachment relationships.

It is not only the primary caregiver, but also the father and siblings bonding which has an influence on the emotional and social development of an individual. When a child is consistently responded for its need, it tends to form a trusting and lifelong relationship.

Many research studies depicts a significant relationship between the parental attachment and later psychological, social development. Securely attached children become more self - reliant and have a better sense of self - esteem. The cognitive - emotional aspect of parental bonding will exert its influence on the adolescence emotional and mental compatibility.

Researchers state that insecure bonding may lead to misinterpretation of failures as an intrinsic fault of themselves. It is also found that isolation during adolescence is the repelling effect of 


\section{Parental Bonding and Psychological Well-Being among Young Adults}

early childhood experiences of insecurity or control. Low care and increased control also increases the risk of depression and lowers the self - esteem of individuals.

\section{Psychological Well - Being}

Psychological well - being is said to be the fundamental of mental health. According to the World Health Organization 2011, mental health is defined as "a state of wellbeing in which every individual realizes his or her own potential, can cope with the normal stresses of life, can work productively and fruitfully, and is able to make a contribution to her or his community”. Traditionally it is said to be the absence of distressful symptoms and includes more positive qualities.

\section{Psychological Well - Being and Parental Bonding}

Research studies show that parental low care and non - engagement or control are associated with lower levels of psychological well - being. They are also prone so neurotic conditions like anxiety, dependency and apprehension. Parents, family and peers have an important role in influencing the psychological well - being of an individual. Parental affection, emotional warmth and empathy serve as determinants of higher well - being and mental health.

Children, adolescents and adults who have a secure attachment with their parents tend to be less prone to psychological strain and distress. It also showed a decreased likelihood or reporting suicidal ideations and attempts. Studies also showed that lack of parental care especially from the mother was reported by almost all the individuals experiencing depression, anxiety disorders and hypochondriasis.

Bowlby (1977) postulated that it is the prime responsibility of parents to provide their children a secure and affectionate base and motivate them in their later years of life to explore ahead. Parental over protection and inadequate control in childhood would result in psychological vulnerability in adult life whereas emotional warmth and high care contributes in lesser strain and higher self-esteem. Hence, all styles have positive or negative consequences, if provided in balance can contribute in the development of a healthy individual.

Parental care or control had an impact on the self - esteem and emotional intelligence of individuals. These factors are those which contribute for better psychological well - being. It is very important for the person who plays the caregiver to be very sensitive and empathetic to the child and develop a warm bonding which would give a sense of security to the child.

Several research studies also states that the early bonding formed by the caregiver and the child, i.e. first $4-5$ years of birth is very important for every individual. Certain parenting patterns are factors influencing the emergence of mental health problems in later stages, which would have an impact on the psychological well - being of the child. Studies show that parenting patterns 


\section{Parental Bonding and Psychological Well-Being among Young Adults}

play a crucial role in the social competence, academic performance and psychosocial development.

Thus it is very important for parents or care givers to have an empathetic and warm bond with their children. There must be a constant level of control and care, which would help the child to have a better psychological well - being.

\section{REVIEW OF LITERATURE}

The study on "Parental practices predict psychological well-being in midlife: life-course associations among women in the 1946 British birth cohort” was to examine the association between well-being in midlife and parental behaviour during childhood and adolescence, and the role of personality as a possible mediator of this relationship. Data from 984 women in the 1946 British birth cohort study were analysed using structural equation modelling. Psychological wellbeing was assessed at age 52 years using Ryff's scales of psychological well-being. Parenting practices were recollected at age 43 years using the Parental Bonding Instrument. Extraversion and neuroticism were assessed at age 26 years using the Maudsley Personality Inventory. In this sample, three parenting style factors were identified: care; non-engagement; control. Higher levels of parental care were associated with higher psychological well-being, while higher parental non-engagement or controls were associated with lower levels of psychological wellbeing. The effects of care and non-engagement were largely mediated by the offspring's personality, whereas control had direct effects on psychological well-being (Huppert, et al 2010).

The study "Self-esteem and life satisfaction as mediators between parental bonding and psychological well-being in Japanese young adults” explored the mediating roles of self-esteem and life satisfaction in the relationship between parental bonding and general mental health among Japanese young adults. Six-hundred-eighty-two undergraduates (358 women and 324 men) completed four measures: Parental Bonding Instrument, Rosenberg's Self-esteem Scale, Satisfaction with Life Scale, and the General Health Questionnaire. A structural equation modelling procedure was used to examine the model of best fit for parental bonding (care and over-protection), life satisfaction, self-esteem, and psychological well-being. Results showed that self-esteem fully mediated the relationship between parental bonding (parental care and parental over-protection) and general mental health. This study demonstrated the mechanism through which perceived parenting style influences Japanese young adults' psychological well-being (Yamawaki, et al 2010).

The current study “Attachment and psychological well-being among adolescents with and without disabilities in Kenya: The mediating role of identity formation” is aimed at evaluating the relationship between attachment and identity development, and their influence on psychological well-being in adolescents with and without disabilities in Kenya. The sample was 


\section{Parental Bonding and Psychological Well-Being among Young Adults}

composed of 296 adolescents (151 with disabilities and 145 without any disability). The mean age in our sample was 16.84 years $(S D=1.75)$. Adolescents with disabilities had significantly lower scores in identity formation, paternal attachment, and life satisfaction. A path model indicated that identity formation partially mediated the relationship between secure attachment and psychological well-being. Our findings indicate that both parent and peer attachment play an important role in the identity formation and psychological well-being of adolescents in Kenya, irrespective of a disabling condition. (Abubakar 2013).

The study "Parent-child relationships and offspring's positive mental wellbeing from adolescence to early older age” examined parent-child relationship quality and positive mental wellbeing using Medical Research Council National Survey of Health and Development data. Wellbeing was measured using Teacher-rated happiness, Life Satisfaction, Satisfaction with home and family life and Diener Satisfaction with Life scale and Warwick Edinburgh Mental Wellbeing scale. The Parental Bonding Instrument captured perceived care and control from the father and mother to age 16, recalled by study members at age 43. Greater well-being was seen for offspring with higher combined parental care and lower combined parental psychological control at all ages. Controlling for maternal care and paternal, maternal behavioural and psychological control, childhood social class, parental separation, mother's neuroticism and study member's personality, higher well-being was consistently related to paternal care. This suggests that both mother-child and father-child relationships may have short and long-term consequences for positive mental well-being. (Stafford 2016)

\section{METHODOLOGY}

\section{Objectives}

1. To assess the style of parental bonding of the sample.

2. To assess the psychological well - being of the sample.

3. To find the relationship between parental care and psychological well - being of the sample.

4. To find the relationship between the parental control and birth order of the sample.

\section{Hypotheses}

The hypotheses are stated as alternate hypotheses, so that they can be either accepted or rejected based on the results.

1. There will be a significant relationship between parental care and psychological well being.

2. There will be a significant relationship between the parental control and birth order of the sample. 


\section{Sample}

60 college students were selected for the study from Sriperumbudur. Simple Random Sampling technique was used for data collection.

\section{Tools}

To collect information from the respondents, the methods of Interview, Case Study Schedule and Psychological Inventories were used. The tools used were as follows:

1. Parental Bonding Instrument - Gordon Parker, Hilary Tupling and L.B. Brown, 1979 Description - The Parental Bonding Instrument (PBI) asks respondents to recall how their parents acted towards them during the first 16 years of their life. The questionnaire consists of 25 items with each item being rated on a 4-point Likert scale from 'very like' to 'very unlike.' Participants are asked to rate their mothers' and fathers' attitudes separately. Parker and associates 1979 reported test-retest reliability scores of .76 for the Care scale and .63 for Overprotection scale, interrater reliabilities of .85 on the care dimension and 69 on the overprotection dimension, and concurrent validity scores of .77 and .78 for the care dimension and .48 and .50 for the overprotection dimension. More recent test-retest reliabilities with a nonclinical U.S. population ranged from .79 to .81, and long-term stability scores ranged between .65 and .77 (Wilhelm and Parker 1990). Reliability analysis of participants' scores on the PBI resulted in participant alpha scores estimating internal consistency of .84 for the Care scale and .84 for the Overprotection scale.

2. Psychological Well - being Index - Olivier Chassany MD. PhD, Elof Dimenäs PhD; Dominique Dubois MD, FFPM and Albert W. Wu MD PhD MPH, 1970

Description - The PGWBI targets peoples' self-representations of an aspect of their general well- being. It does not include an evaluation of physical health. The 22 item instrument includes six dimensions: Anxiety, Depressed Mood, Positive Well-being, SelfControl, General Health and Vitality. The 22 items are frequently used to generate an overall Index or total score for general well-being. The questionnaire takes 10 minutes or less to administer and is generally well-accepted. Internal consistency reliability levels of the PGWB and PGWB-R were comparable, with Cronbach's alpha coefficients between 0.93-0.96 for the total scale across method of administration. Intraclass correlations between the two methods were high $(0.66-0.84)$. The PGWBI scale has satisfactory internal construct validity when tested with modern psychometric techniques.

\section{Analysis of the Data}

The data was analyzed statistically using SPSS package 22.0v.

1. One way ANOVA

2. Pearson Product Moment Correlation 
RESULTS AND DISCUSSION

TABLE-I Mean and Standard Deviation of Parental Care, Parental Control and Psychological Wellbeing

\begin{tabular}{|l|c|c|c|c|}
\hline \multicolumn{1}{|c|}{ Variable } & Mean & Standard Deviation & t Value & Significance \\
\hline Parental Care & 21.86 & 5.48 & 35.433 & $<0.01^{* *}$ \\
\hline Parental Control & 18.56 & 9.01 & 20.215 & $<0.01^{* *}$ \\
\hline Well-being & 59.27 & 8.45 & 32.107 & $<0.01^{* *}$ \\
\hline
\end{tabular}

**Significant at 0.01 level

The table indicates that the variables of the study namely Parental Care, Parental Bonding and Psychological Well - Being differ across the sample. Thus the scores are normally distributed across the samples. The scores of all the variables are significant at 0.01 levels.

TABLE - II Differences on Parental care and Parental Control based on Psychological Well-being

\begin{tabular}{|l|c|c|}
\hline \multicolumn{1}{|c|}{ Variable } & F Value & Significance \\
\hline Parental Care & 5.570 & $<0.01^{* *}$ \\
\hline Parental Control & 10.501 & $<0.01^{* *}$ \\
\hline
\end{tabular}

**Significant at 0.01 level

The above table exhibits the differences on parental care and control based on Psychological Well - being. It indicates that the sub - variables of parental bonding namely Care and Control are significant at 0.01level on psychological well - being. Thus the results support the attachment theory of Bowlby, which postulates that the attachment of a child with caregivers have an influence on the development of the child in all multidimensionality.

TABLE - III Correlation between Parental Care, Parental Control and Psychological Well-being

\begin{tabular}{|l|c|c|c|}
\hline & Parental Care & Parental Control & Psychological Well-being \\
\hline Parental Care & 1 & & $-0.594^{* *}$ \\
\hline Parental Control & & 1 & $-0.548^{* *}$ \\
\hline
\end{tabular}

**Significant at 0.01 level

In the above table Pearson Product Moment Correlation was used to calculate the relationship between Parental Care, Control and Psychological Well - being. There exists a negative correlation between parental care and psychological well - being. Thus when care increases, psychological well - being decreases and vice versa. There also negative correlation between parental control and psychological well - being. Thus when control increases, psychological well - being decreases and vice versa. Hence the sub - variables of parental bonding have a significant relationship on psychological well - being. 


\section{SUMMARY AND CONCLUSION}

The scores of the variables are found to be normally distributed. They are significant at 0.01 levels. Based on Psychological Well - Being, the sub - variables of Parental Bonding such as Care and Control tend to be significant at 0.01 levels.

There exists a significant negative correlation between parental care and psychological well being. There also exists a significant negative correlation between parental care and psychological well - being.

\section{Acknowledgments}

The author appreciates all those who participated in the study and helped to facilitate the research process.

Conflict of Interests: The author declared no conflict of interests.

\section{REFERENCES}

Amichai-Hamburger, Yair (2009), Technology and Psychological Well-being. Cambridge University

Amina Abubakar (2013). Attachment and psychological well-being among adolescents with and without disabilities in Kenya: The mediating role of identity formation, Journal of Adolescence 36(5):849-57. Retrieved from

https://www.researchgate.net/publication/256467108_Attachment_and_psychological_w

ell-being_among_adolescents_with_and_without_disabilities_in_Kenya_The_

mediating_role_of_identity_formation

Holden, G.W. (2010). Parenting, Sage publications

Huppert FA1, Abbott RA, Ploubidis GB, Richards M, Kuh D (2010), Parental practices predict psychological well-being in midlife: life-course associations among women in the 1946 British birth cohort. Retrieved from http:/www.ncbi.nlm.nih.gov/pubmed/19995477

Huppert, Felicia A. (2011), Happiness and Well-being. Vol 4, Routledge Press

Hurlock, E.B. (1988). Developmental psychology. Tata Mc Graw- Hill, Publications.

Niwako Yamawaki, Julie Ann Peterson Nelson and Mika Omori (2011), Self-esteem and life satisfaction as mediators between parental bonding and psychological well-being in Japanese young adults, Article Number - A42596514325, Retrieved from http://www.academicjournals.org/journal/IJPC/article-abstract/A42596514325

Social Determinants of Health and Well- being Among Young People (2012), World Health Organization

Stafford M, Kuh DL, Gale CR, Mishra G, Richards M (2016). Parent-child relationships and offspring's positive mental wellbeing from adolescence to early older age. Volume 11, Issue3, Retrieved from http://www.tandfonline.com/doi/full/10.1080/17439760.2015.1081971. 


\section{Parental Bonding and Psychological Well-Being among Young Adults}

V.Brett, Brown (2008), Key Indicators of Child and Youth Well-Being. Psychology Press

How to cite this article: Indumathy J, Ashwini K (2017), Parental Bonding and Psychological Well-Being among Young Adults, International Journal of Indian Psychology, Volume 4, Issue 2, No. 92, ISSN:2348-5396 (e), ISSN:2349-3429 (p), DIP:18.01.109/20170402, ISBN:978-1365-78192-6 